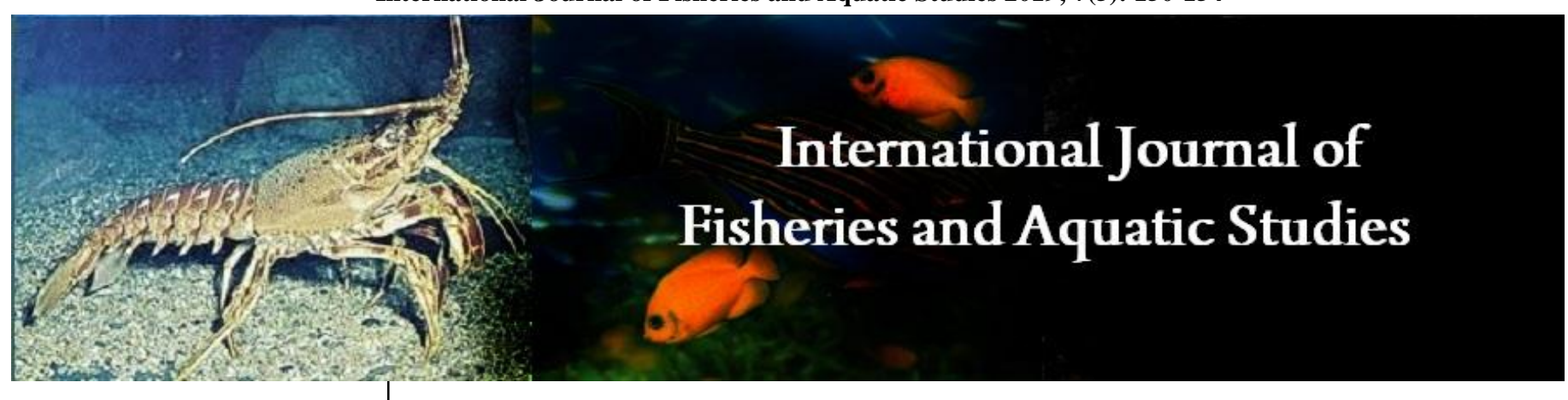

E-ISSN: 2347-5129

P-ISSN: 2394-0506

(ICV-Poland) Impact Value: 5.62

(GIF) Impact Factor: 0.549

IJFAS 2019; 7(5): 150-154

(C) 2019 IJFAS

www.fisheriesjournal.com

Received: 11-07-2019

Accepted: 15-08-2019 Associate Professor, Zoology Degree College, Kasganj,

Uttar Pradesh, India
Dr. Sudhir Kumar Rawat Department, Government

\section{Comparative analysis of the predatory habits of Gambusia and Poecilla fishes in environmental control of mosquitoes}

\section{Dr. Sudhir Kumar Rawat}

DOI: $\underline{\text { https://doi.org/10.22271/fish.2019.v7.i5b.2593 }}$

\begin{abstract}
Adult Gambusia could eat up to 150 mosquito larvae in an eight-hour period. This makes them an excellent biological tool for mosquito control because they eat the larvae before they have a chance to develop into adult mosquitoes. However, the use of Gambusia and Poecilla /guppy fish as biological weapons to control mosquito menace have had also been reported to have the opposite effect as well.
\end{abstract}

Keywords: predatory habits, Gambusia and Poecilla fishes, mosquitoes

\section{Introduction}

The mosquitos were become a threat to the mankind in a different way by introducing dengue and malaria like highly infectious disease which leads to the decrease in immunity of a person. In order to fight these the ecologist suggested larva gobbling fishes who feeds on the mosquito larva in ponds where they grow in thousands number eradicate the mosquito threat biologically. And the little guppy Poecilla reticulata has developed a big reputation. For decades, the fish has been championed as a mosquito fighter and dumped into ponds and ditches to eat up the insect's larvae. But among scientists, it has a different reputation-as an invasive species with a remarkable ability to reproduce and spread. Now, as health officials in regions facing mosquito-borne viruses consider expanding use of these predatory fish, ecologists are urging them to think twice. In a paper published online today in Biology Letters, a group of ecologists argues that the guppies - and other nonnative fish used for mosquito control-haven't actually proven very effective mosquito fighters, but are known to pose ecological risks. "It all sounds like it's magical-you put the guppies in, they eat the mosquitoes, everything is fine," says Rana El-Sabaawi, an ecologist at the University of Victoria in Canada and lead author on the new paper. "Our concern is that you have a potentially invasive species that is being introduced haphazardly."

Larva-gobbling guppies may have been cutting-edge technology for U.K. colonialists aiming to rid the empire of mosquitoes at the turn of the century. While "randomly Googling guppies," she came across news reports from Pakistan that health officials had released thousands of the fish into the ponds and sewers of Karachi in 2013 to fight the transmission of dengue fever. Guppies are efficient invaders. They're hearty and fertile, surviving in relatively polluted water, reproducing often, and giving birth to fast-growing, live young. A combination of accidental aquarium releases and mosquito control projects have spread the species from its native range in the Caribbean and the northern coast of South America to at least 69 countries, according to a 2011 survey.

\section{Advantages of this type of fish}

- These fishes are self-perpetuating after their establishment and continue to reduce mosquito larvae for a long time.

Corresponding Author: Dr. Sudhir Kumar Rawat Associate Professor, Zoology Department, Government Degree College, Kasganj,

Uttar Pradesh, India
- The cost of introducing larvivorous fish is relatively lower than that of chemical control.

- The use of fish is an environmentally friendly method of control.

- Larvivorous fish such as Gambusia and Poecilla prefer shallow water where mosquito larvae also breed. 


\section{Breeding season of fish}

Gambusia breeds throughout the year after maturity, especially in tropical conditions. In relatively colder climates such as is found in the north and north-west India breeding period lasts from May to September and in the warmer climate of southern India from April to November.

\section{Experimental design}

As suggested by the breeding season of these fishes the fishes needs more protein source before breeding so the best time to introduce these fishes for experiments were selected to Aprilmay months. The three ponds were created with equal amount of mosquito larvas in it. The equal amount of fishes was introduced in each ponds and one pond has been subjected to equal amount of each fish. Each pond has been set in experimental setup for certain period during mosquitoes breeding condition.

Table 1: The feeding tendency of the Gambusia and Poecilla fishes in control pond

\begin{tabular}{|c|c|c|c|c|c|c|c|}
\hline Fishes & Eggs & 1 st instar larva & 2 nd instar larva & 3 rd instar larva & Juvenile larva & Adult larva & Total \\
\hline Control & 100 & 100 & 100 & 100 & 100 & 100 & 600 \\
\hline Gambusia & 71 & 75 & 66 & 22 & 15 & 7 & 256 \\
\hline Poecilla & 82 & 25 & 31 & 40 & 49 & 60 & 287 \\
\hline Gambusia and Poecilla & 44 & 15 & 22 & 17 & 12 & 14 & 124 \\
\hline
\end{tabular}

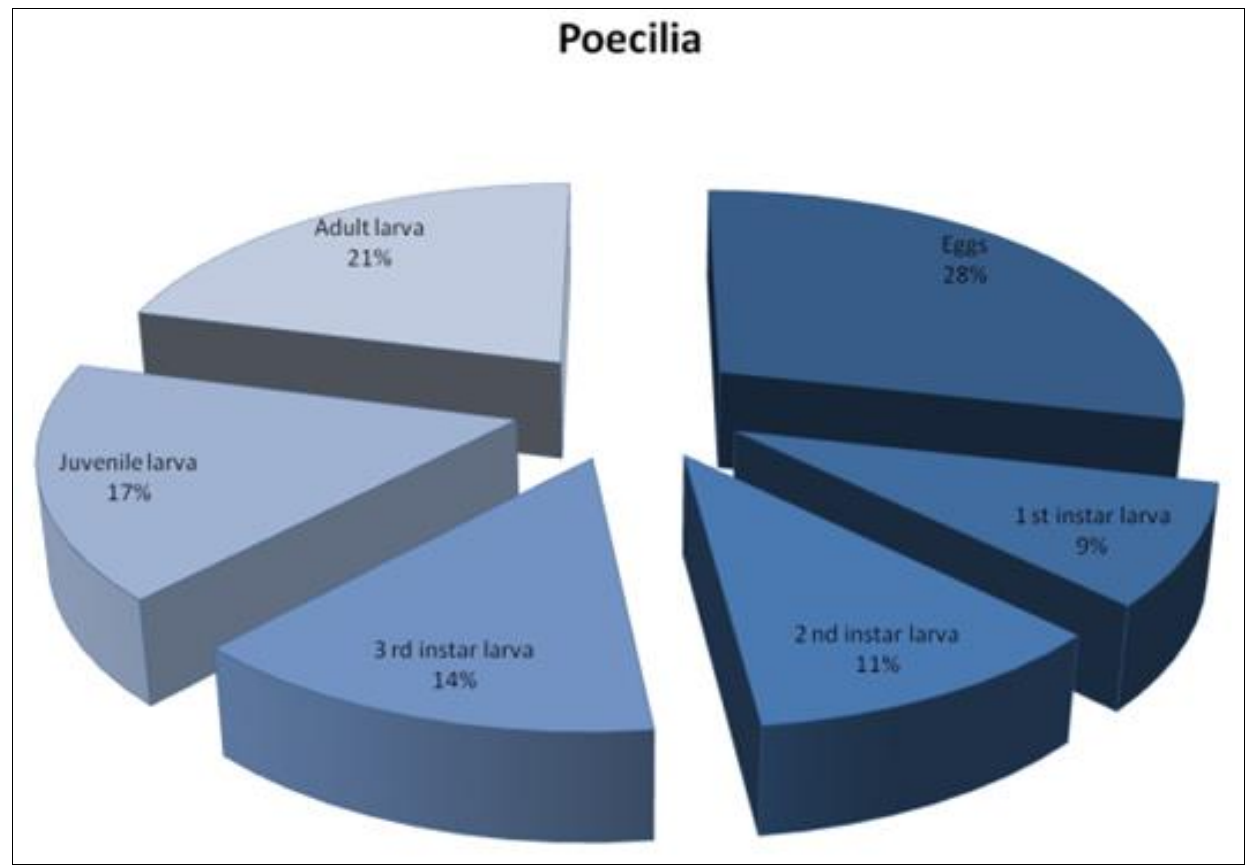

Fig 1: The feeding habits of Gambusia on mosquito larva

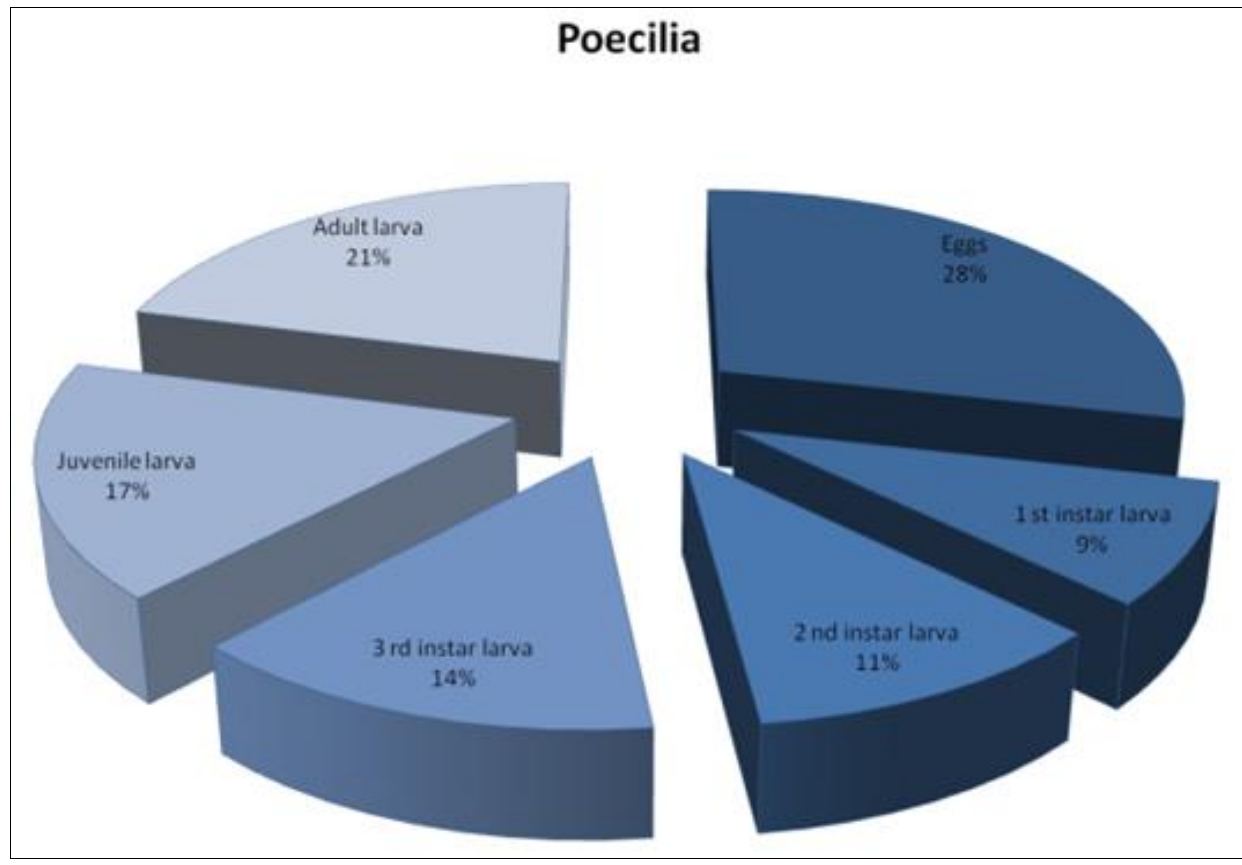

Fig 2: The feeding habits of Poecilla on mosquito larva 


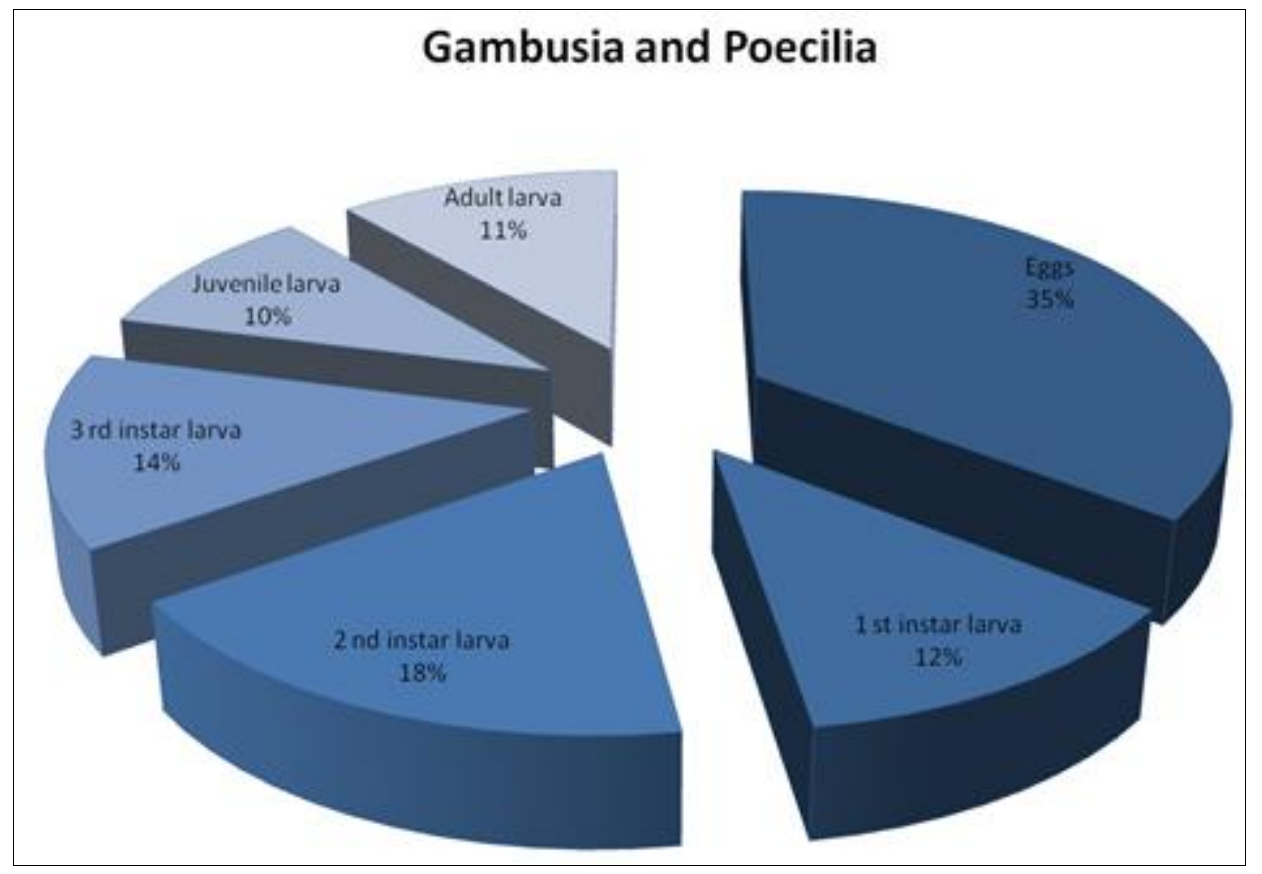

Fig 3: The feeding habits of both predatory fishes on mosquito larva
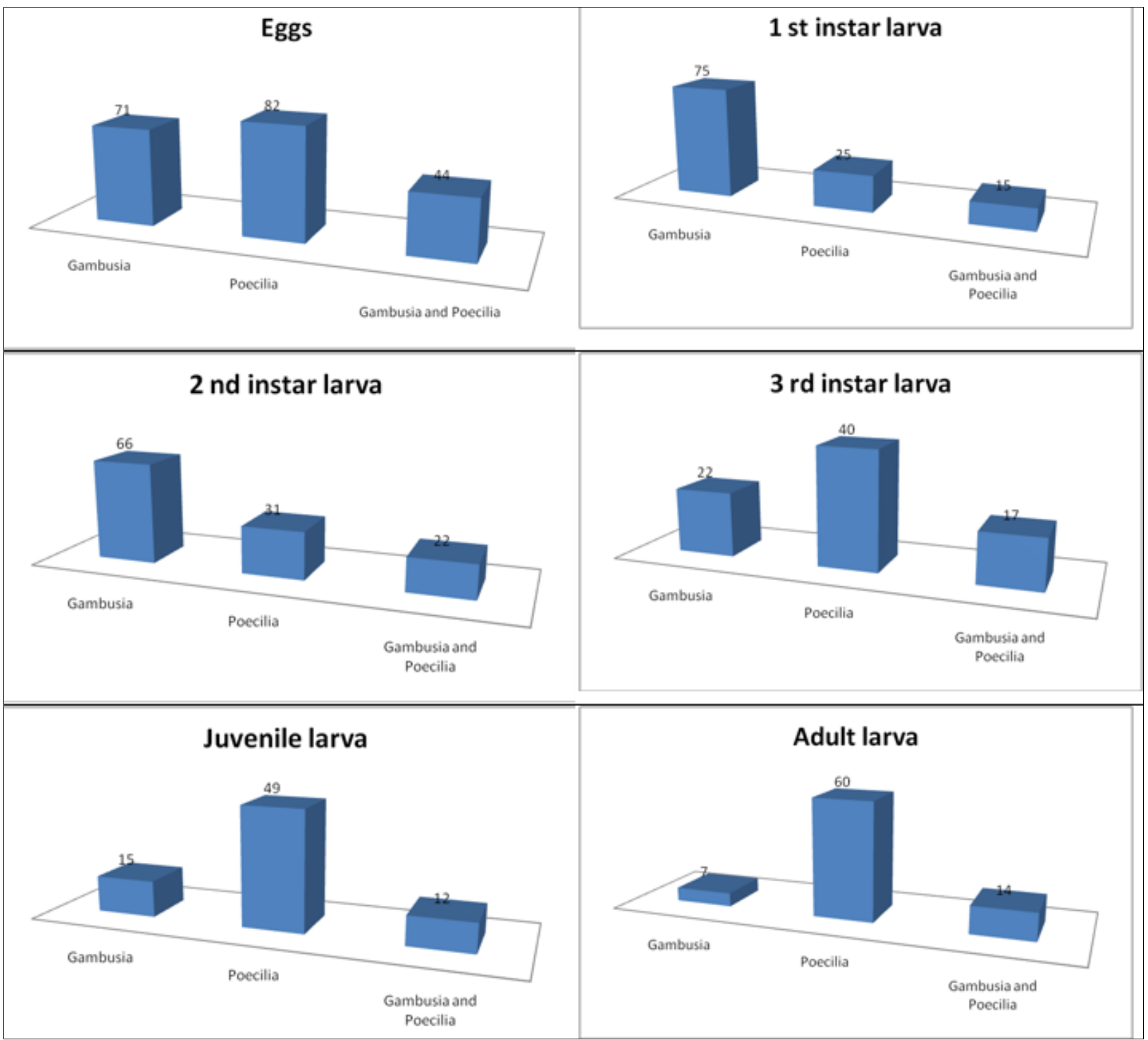

Fig 4: Comparative predatory effect of both fishes individual and in combination on different mosquito larva stages 


\section{Result and Discussion}

Under laboratory conditions Poecilla was more successful than Gambusia in preying upon the 3rd, 4th and pupal stages of mosquitoes. The reverse was found for the first two instars. However. Poecilla consumed more 2 nd instar larvae under the cover of vegetation when larger fish were able to penetrate shallow water and feed on the mosquito larvae. The two species showed a similar prey-size selection except for Poecilla of the medium size $(31-35 \mathrm{~mm})$ which ate larger larvae than Gambusia of the same size range. When provided access to the surface, neither fish species showed any adverse effect at oxygen levels as low as $0.5 \mathrm{mg} \mathrm{l-1} \mathrm{(6 \%} \mathrm{saturation).}$ When denied access to the surface, both species behaved 'normally' at oxygen levels as low as $1.3 \mathrm{mg} 1-1$ (15\% saturation).

\section{Conclusion}

This study suggests that Gambusia affinis and Poecilla reticulata can complement each other as mosquito control agents in different habitat conditions. We suggest that in mosquito infested situation which are characterized by high organic matter and low oxygen levels biological control could best be achieved by introduction of a range of sizes of both fish species. Repeated introductions of the fish, in large enough numbers, may be required for ad-hoc alleviation of a mosquito problem. Best results are thus to be expected in relatively small water bodies such as oxidation ponds.

\section{References}

1. Ahmed YA, Isaq A. Field trial on the impact of Oreochromis spilurus spilurus on malaria transmission in northern Somalia. W.H.O. EM/MAL/191 EM/SOM/ MPD/001/RB 1982, 25.

2. Haas R, Pal R. Mosquito larvivorous fishes. Bull. ent. Soc. Am 1984;30:17-25.

3. WHO. Manual on environmental management for mosquito control with special emphasis on malaria vector. World Health Organization, Publ. No. 66, Geneva 1982, 283.

4. Blaustein L. Larvivorous fishes fail to control mosquitoes in experimental rice plots. Hydrobiologia 1992;232:219232.

5. Angerilli NPD. The influences of extract of freshwater vegetation on the survival and oviposition by Aedes aegypti. Can. Ent 1980;112:1249-1252.

6. WHO. Report of the travelling seminar on the use of larvivorous fish for mosquito control in anti malaria campaigns. Golden Sands Bulgaria/Tbilisi Georgian Republic, SSR, USSR. EM/VBC/22: EM/TR.SMR. LRV.FSH.MSQ.CTR/14, 1979, 1980, 35.

7. Byniak E. Influence of day length and temperature on the reproduction of Aphanius mento (Cyprinodontiformes, Teleostei). Ph. D. Thesis, Hebrew University, (in Hebrew) 1973, 96.

8. Wurtsbaugh WH, Cech JJ Jr. Growth and activity of juvenile mosquitofish: Temperature and ration effects. Trans. am. Fish. Soc 1983;112:653-660.

9. Wurtsbaugh WH, Cech JJ, Compton J. Effect of fish size on prey size selection in Gambusia affinis. Proc. 48th Ann. Conf. Calif. Mosq. vector cont. Ass 1980, 48-51.

10. Angerilli NPD, Berine P. Influence of aquatic plants on colonisation of artificial ponds by mosquitoes and their insect predators. Can. Ent 1980;112:793-796.

11. Blaustein L. Spatial distribution of Anopheles freeborni,
Gambusia affinis and Lepomis cyanellus in experimental rice plots. J am. Mosq. Control Ass 1989;5:254-257.

12. Carlson DB, Vigliano RR, Wolfe GL. Distribution of mosquitoes in different wastewater stages of secondarily treated domestic effluent and untreated citrus wastewater. J. Am. Mosq. Control Ass 1986;2:516-521.

13. Castleberry DT, Cech JJ. Mosquito control in wastewater: a controlled and quantitative comparison of pupfish (Cyprinodon nevadensis amargosae), mosquito fish (Gambusia affinis) and guppies (Poecilla reticulata) in Sago pondweed marshes. J am. Mosq. Control Ass 1990;6:223-228.

14. Chapman HC. Biological control of mosquito larvae. Ann. Rev. Ent 1974;19:33-59.

15. Schaefer $\mathrm{CH}$, Miura T. Mosquito breeding in a cat tail marsh used for treatment of secondary sewage effluent. In B. Tabraham \& J. Coates (eds.) Mosquito Res. Control Board Annual Report. Univ. Calif. Division of Agriculture and Natural resources, Berkley CA 1985, 8082.

16. Walters LL, Lenger EF. Impact of the desert pupfish, Cyprinodon macularius and Gambusia affinis affinis on fauna in pond ecosystems. Hilgardia 1980;48:1-18.

17. Zaman MS. Malaria control through fish. Pakistan J Sci 1980;32:163-168.

18. Crowder LB. Community ecology. In Schreck, C. B. \& P. B. Moyle (eds). Methods for fish biology. Am Fish. Soc. Bethesda, Maryland 1990, 609-627.

19. El Safi SH, Haridy AAM, Rabaa FMA. The food of the larvivorous fish Gambusia affinis (Baird and Girard) and Oreochromis (formerly Tilapia) niloticus (Linnaeus) in Gezira irrigation canals. J trop. med. hygien 1985;88:169-174.

20. Hess AD, Tarzwell CM. The feeding habits of Gambusia affinis affinis with special reference to the malaria mosquito, Anopheles quadrimaculatus. Am. J Hygien 1942;35:142-151.

21. Hoy JR, Kauffman EG, O'Berg AG. A large scale field test of Gambusia affinis and Chlorpyrifos for mosquito control. Mosq. News 1972;32:161-171.

22. Hurlbert SH, Zedler J, Fairbanks D. Ecosystem alteration by mosquitofish (Gambusia affinis) predation. Science 1972; 175:639-641.

23. Houston BN, Dancer BN, Learner MA. Control of sewage filter flies using Bacillus thuringiensis var. israelensis I. Acute toxiticy tests and pilot scale trials. II. Full scale trials. Wat. Res 1989;23:369-385.

24. Jones JC. The feeding behavior of mosquitoes. Sci Am 1978;238:112-121.

25. Krumholtz R. Reproduction in the western mosquitofish Gambusia affinis and its use in mosquito control. Ecol. Monogr. Durham, North Carolina 1948;18:1-43.

26. Margalit J, Pascar-Gluzman C. Bobroglio H, Barak Z. Biocontrol of mosquitoes in Israel. Integrated Mosquito Control Methodologies 1985;2:361-374.

27. Mortenson EW. Mosquito occurrence in wastewater marshes: a potential new community problem. Proc. Pap. Ann. Conf. Calif. Mosquito Vector Control Ass 1982;50:65-67.

28. Mulla MS, Darwazeh HA, Dhillon MS. Impact and joint action of decamethrin and permethrin and fresh water fishes on mosquitoes. Bull. environ. cont. tox 1981;26:689-695.

29. Nasir AS. History of the use of larvivorous fish for larval 
control in Somalia. W.H.O. EM/TR. SMR. LRV. FSH. MSQ. CTR/Somalia 1979a, 3.

30. Nasir AS. Important species of fish used for larval control in the Anti-Malaria Program in Somalia, with special reference to Tilapia zilli and Nothobranchius palinquisti. W.H.O. EM/ST. SMR. FSH. MSQ. CTR/7.3 Somalia 1979b, 9.

31. Pant CP, Rishikesh N, Bang YH, Smith A. Progress in malaria vector control. Bull. W.H.O 1981;59:325-333.

32. Goren M. The freshwater fishes of Israel. Biology and Taxonomy. Hakibuz Hamehuchad Publishing House. Tel Aviv 1983, 102 (In Hebrew).

33. Haas R. Guide for preliminary identification of some larvivorous fish. W.H.O. VBC/84.1, 1984, 44. 